A National Study of Differences between Online and Classroom-Only Community College Students

in Time to First Associate Degree Attainment, Transfer, and Dropout

\title{
A National Study of Differences between Online and Classroom-Only Community College Students in Time to First Associate Degree Attainment, Transfer, and Dropout
}

\author{
Peter Shea \\ University at Albany, State University of New York \\ Temi Bidjerano \\ Furman University
}

\begin{abstract}
Previous research indicates that online learning at the community college level results in higher rates of withdrawal, failure, and dropout compared to classroom-based education (Xu \& Smith Jaggars, 2011; Smith-Jaggars \& Xu, 2010). The primary goal of the current study was to examine national data (US Dept. of Ed. Beginning Postsecondary Student Survey, 2004-09) on three outcomes for community college students with and without online education experiences. The outcomes were attainment of first associate degree, transfer, and dropout. In contrast to previous research, compared to exclusively classroom-based students, results suggest significantly more students who had engaged in online education had attained an associate degree at the end of the observation period. There were no significant differences in transfer or dropout. These results are interpreted with regard to their implications for policy and practice.
\end{abstract}

College completion is a goal that has attained significant attention in recent years. Recognizing that a college credential is increasingly a prerequisite to individual economic advancement and collectively, to national prosperity, the efforts of numerous foundations and both federal and state-level initiatives have resulted in a wide-ranging college completion agenda in the US (Russell, 2011). The immediate roots of these efforts can be found in data indicating that in the coming decade a majority of jobs will require a post-secondary credential. Relative to other developed nations, the US lags in degree attainment, especially among younger citizens (Sparks, 2011). Formerly occupying the number two position, the U.S. now ranks 12th among 37 OECD countries in the percentage of 25-34 year-olds with higher education credentials (OECD, 2013). Compounding the problem, reports from the National Center for Education Statistics indicate that the number of degrees conferred is not forecast to grow significantly (NCES, 2011). 
A National Study of Differences between Online and Classroom-Only Community College Students in Time to First Associate Degree Attainment, Transfer, and Dropout

The relatively new degree completion agenda has eclipsed previous and longstanding efforts aimed more specifically to increase access to higher education. While increasing access has been a multifaceted undertaking, with a history that goes back at least to the GI Bill and the development of the community college system (Vaughan, 2006), much recent effort has focused on the uses of technology, especially online education as a means to make higher education more accessible.

More than 6.7 million college students enrolled in a traditional, credit-bearing online courses in 2012 (Allen \& Seaman, 2013), a figure that represents more than one in three of every college student in the United States. Online and distance education have long been seen as a vehicle for democratization (Larreamendy-Joerns \& Leinhardt, 2006) and increased access and have been adopted very broadly among institutions with an access mission; chief among these are community colleges. Of all students enrolled in online courses in the US, the majority of these were enrolled at the community college level (Parsad \& Lewis, 2008; Radford, 2011). However, the expansion of traditional online education among community college populations has generated concern among some specifically regarding poor outcomes of online community college students relative to classroom students. Central to this analysis is the possibility that online learning has impeded rather than enhanced degree completion rates, especially among students in associate degree programs.

The prominent line of research on this topic has examined large samples of online learners in two different state systems (Smith Jaggars \& Xu, 2010; Xu \& Smith Jaggars, 2011) and arrived at several disappointing results. Reviewing data on approximately 24,000 students in 23 institutions in the Virginia Community College system, Smith Jaggars and Xu (2010) concluded that learners had were more likely to fail or withdraw from online courses than from face-to-face courses. The authors also found that students who took online coursework in early semesters were somewhat less likely to return to school in following semesters, and students who took a higher proportion of credits online were slightly less likely to attain a college credential or transfer to a four-year institution.

Xu \& Smith Jaggars (2011) also studied the Washington State Community College Systems and came to similar conclusions. Analyzing data from more than 51,000 students in 34 community and technical colleges, $\mathrm{Xu} \&$ Smith Jaggars concluded that although students with better educational preparation were more likely to enroll in online courses, these students were also significantly more likely to fail or withdraw from these courses than students who took traditional face-to-face classes. Students in the Washington State Community College system who took more online courses were also slightly less likely to complete a degree or transfer to a four-year college than those who took fewer online courses.

Additionally, online learning appears to accentuate achievement gaps. For example, recent studies found that while all learners at the community college level experience worse outcomes in fully online courses, certain sub-groups show a sharper decline including males, students with lower prior GPAs, and African American students (Jaggars, Edgecombe, \& Stacey, 2013; Xu \& Jaggars, 2013).

Taken together, these studies do not support a cost-effective strategy of promoting degree completion in community college through traditional online education. If the results from these studies are generalizable to a national population, the findings have numerous and significant financial implications. For example, the higher rate of failure and withdrawal from online courses extends the time needed to complete a college credential making online learning less efficient and thus costlier for degree attainment. This is of concern given that previous studies have concluded that spending on community college students has had a particularly poor return with regard to degree completion. For example, the Delta project (Kirshtein \& Wellman, 2012) concluded that "nearly half of instructional spending in community colleges goes to students (and credits) that do not attach to a degree or certificate" (p. 16). Given the high costs associated with lower and slower completion rates, it is reasonable to infer that online learning may produce more college students but fewer students with college credentials. Adding to 
A National Study of Differences between Online and Classroom-Only Community College Students in Time to First Associate Degree Attainment, Transfer, and Dropout

these challenges is the corresponding likelihood that online education results in a slower time to degree. This would indicate that online education is both less efficient and effective in achieving widely valued goals of producing more college graduates in the US. Previous research (Shea \& Bidjerano, 2014) presented an analysis that disputes findings that online education results in lower degree completion rates. The present study examines whether students who studied in online education early in their college careers also required additional time to complete a college credential, were less likely to transfer, or dropped out at higher rates.

To accomplish this goal, the current study examines national, rather than State-level community college student data. While it appears that conclusions drawn from the students in Virginia and Washington don't hold great promise with regard to online learning, it may be that national data yield different results. We therefore utilize data from the US Department of Education's Beginning PostSecondary Survey (04/09) to determine if national trends are at variance with results from analysis of large-scale State level data.

To understand whether national, rather than State-level data yields different results, the primary goal of the current study was to examine three related educational outcomes for community college students with and without traditional online education experiences during their year of first entry in postsecondary education. For the purpose of this study, we define online students as those students who had taken at least one online course and classroom-only students as those students who had never taken an online course. The outcomes of interest were attainment of first associate degree, transfer, and dropout. While other studies have provided precise estimates of degree completion, dropout, and transfer rates for the overall population of community college students (e.g., National Center for Education Statistics, 2010), few studies (e.g., Scott \& Kennedy, 2005) have investigated time processes for these three critical outcomes. In addition, no studies involving direct comparisons between online and classroom-only students in terms of time-to-graduation, time-to-transfer, and time-to-dropout have been reported in the literature.

The purpose of the study was primarily descriptive. The goal was to describe the timing of the three events and to compare the time trajectories of the subpopulations of community college students with and without exposure to online education coursework during their first year of study. The study examined also whether the time-to-event processes within subpopulations vary as a function of demographic characteristics.

\section{Method}

\section{Participants}

The study uses data from Beginning Postsecondary Students (BPS 04/09) study conducted by the National Center for Education Statistics. The original BPS 04/09 sample includes records of approximately 16,100 students representing about 4,000,000 individuals who have entered postsecondary institutions in the 2003/04 academic year. The analytical sample for this study consisted of approximately 4,400 community college students. The primary focus in this study was on time-to-degree, dropout rates, and transfer relative to the community college institution of first entry; therefore, the sample was delimited to community college students whose records in 2003/04 as well as student survey data identified an associate degree as a program of study. Community college students on paths of a certificate degree or a bachelor's degree and students not pursuing a degree were excluded. In addition, of the subpopulation of eligible students, a small subset of students without an earned high school diploma was excluded. Table 1 present the demographic characteristics of the population represented by the 
A National Study of Differences between Online and Classroom-Only Community College Students in Time to First Associate Degree Attainment, Transfer, and Dropout

sample. About $13 \%$ ( $\mathrm{n} \approx 540$ ) of these students were either in an online education program or had taken online courses during the first year of their study.

Table 1

Percentages for Select Demographic Variables $(N \approx 4,400)$

\begin{tabular}{|c|c|c|c|}
\hline Demographics & Online Education & No Online Education & Total \\
\hline \multicolumn{4}{|l|}{ Gender } \\
\hline Male & 35.29 & 43.69 & 42.58 \\
\hline Female & 64.71 & 56.31 & 57.42 \\
\hline \multicolumn{4}{|l|}{ Age } \\
\hline$\leq 21$ & 63.45 & 70.67 & 69.72 \\
\hline$>21$ & 36.55 & 29.33 & 30.28 \\
\hline \multicolumn{4}{|l|}{ Race } \\
\hline White & 66.21 & 59.63 & 60.50 \\
\hline Black & 9.42 & 15.75 & 14.92 \\
\hline Hispanic & 14.69 & 15.16 & $15 / 10$ \\
\hline Asian & 4.51 & 4.52 & 4.51 \\
\hline Other & 5.81 & 4.94 & 4.97 \\
\hline \multicolumn{4}{|l|}{ Risk } \\
\hline$\leq 2$ Risk Factors & 59.45 & 64.61 & 63.93 \\
\hline >2 Risk Factors & 40.55 & 35.39 & 36.07 \\
\hline \multicolumn{4}{|l|}{ SES } \\
\hline$<35,000$ & 47.04 & 47.63 & 47.55 \\
\hline $35,001-75,000$ & 34.80 & 34.86 & 34.85 \\
\hline$>75,001$ & 18.16 & 17.50 & 17.59 \\
\hline
\end{tabular}

Note. The variable risk factor is a composite of seven indicators: delayed enrollment, financial independence, work while enrolled, no high school diploma, part time enrollment, single parent status and no dependents.

\section{Data Analysis}

To analyze the time patterns for the subpopulations of students, we used competing risks discrete survival analysis (known also as event-history analysis in the literature). Competing risks survival analysis is the best methodological approach for analytic situations in which there are multiple possible outcomes under study, precise estimates of timing of outcomes of interest are sought to account for individuals whose participation is discontinued for reasons unrelated to the outcomes of interest (censoring), and cumulative measures of outcomes of interests are to be determined (Muthén \& Masyn, 2004; Scott \& Kennedy, 2005; Singer \& Willett, 2003). In the survival methodology, the outcomes under investigation are referred to as events and the goal is to determine the probability (risk or hazard) of an event occurring in a given time interval. In the context of competing risk discrete survival analysis, participants at risk in a time period are the individuals in a given time period who have not experienced any of the competing events in prior periods and have not been censored (i.e., have not discontinued participation in the study). In other words, the risk set does not include those who have already experienced the event(s) or data on whom are missing (i.e., the individuals have been censored). Hazard probabilities are estimated for each time period and each study event. When a single event is analyzed, the hazard probability of an event for a time interval represents the probability of an event occurring for the participants at risk (the participants have not experienced the event in a prior period or have not 
A National Study of Differences between Online and Classroom-Only Community College Students in Time to First Associate Degree Attainment, Transfer, and Dropout

experienced any of the alternative events under investigation). For our purposes, survival probability is the proportion of individuals in the risk dataset who at the end of a time segment remain unaffected by any of the competing events (transfer, graduation, or dropout) or have not been removed from the study because of missing data (Muthén \& Masyn, 2004; Singer \& Willett, 2003). Survival probability is often of interest in single events analysis but considered irrelevant in multiple events situations (Scott \& Kennedy, 2005). When there are multiple events under investigation, a cumulative hazard probability for each event can be estimated to allow inferences about the proportion of the initial population that has experienced each event by a given time period (Scott \& Kennedy, 2005). While the method refers to hazards, and is often applied in safety and risk management contexts, in this analysis we are estimating the likelihood of degree completion using this approach.

The competing events of interest in this discrete competing risk analysis were: (1) attainment of first associate degree in the primary institution of first entry, (2) dropout from the institution of first entry, and (3) downward, lateral, or upward transfer. Because community college students are a highly transient population and often show variable enrollment patterns (e.g., part time enrollment, official withdrawal followed by re-enrollment, and stopouts for an extended period of time without dropout), the most recent indicators of degree attainment, transfer, and student dropout status (recorded in June of 2009) were used to determine the actual timing of the events. Table 2 shows all possible outcomes for the 6-year observation period.

Table 2

Six-year Outcomes for the Subpopulation $(N \approx 4,400)$

\begin{tabular}{lrrr}
\hline Six-year outcome & Online Education & No Online Education & Total \\
\cline { 2 - 3 } First Institution & & & \\
Dropout & $31.76 \%$ & $36.73 \%$ & $36.08 \%$ \\
Enrolled & $6.57 \%$ & $9.41 \%$ & $9.04 \%$ \\
Certificate & $3.61 \%$ & $3.34 \%$ & $3.38 \%$ \\
Associate & $17.23 \%$ & $13.27 \%$ & $13.79 \%$ \\
Transfer Institution(s) & & & \\
Dropout & $11.82 \%$ & $9.32 \%$ & $9.65 \%$ \\
Enrolled & $9.93 \%$ & $10.99 \%$ & $10.85 \%$ \\
Certificate & $2.62 \%$ & $2.89 \%$ & $2.85 \%$ \\
Associate & $2.24 \%$ & $2.75 \%$ & $2.68 \%$ \\
Bachelor's & $14.23 \%$ & $11.30 \%$ & $11.68 \%$ \\
Total & $100 \%$ & $100 \%$ & $100 \%$ \\
\hline
\end{tabular}

The survival methodology requires a clear definition of unit of time. The timing of the three events was recorded in intervals of one academic year, defined as the time span from the month of July in a given calendar year to the month of June in the following calendar year. This resulted in 6 time periods/ time intervals (Year 1: July 03-June 04; Year 2: July 04-June 05; Year 3: July 05-June 06; Year 4: July 06-June 07; Year 5: July 07-June 08, and year 6: July, 08-June, 09). Academic year was chosen as a unit of analysis because previous research has indicated that events such as degree completion, dropout, and transfer typically occur in the spring semester of each academic year (Scott \& Kennedy, 2005); therefore, 
A National Study of Differences between Online and Classroom-Only Community College Students in Time to First Associate Degree Attainment, Transfer, and Dropout

inclusion of intervals with shorter duration was deemed unlikely to offer additional insight into the timeto-events processes.

\section{Results}

The estimated hazard probability profiles by type (at least one online course vs. no online courses) are shown in Figure 1. The hazard probability profiles illustrate the difference in the proportions of degree attainment, dropout, and transfer within each year for the students who have remained unaffected by these events in prior years. The profiles for the two subpopulations exhibit similar patterns for years 1, 2 and 4. For both online and classroom-only students, the risk for transfer and dropping out outweigh the chances of degree attainment in the first two years. In year 3, the chances of attaining an associate degree and dropping out equalize for the online students but remain relatively low compared to the risk of dropping out. In the same year, the proportion of classroom-only students graduating is substantially lower than the proportions of transfers and dropouts.

For both types of students, chances for transfer declines in years 5 and 6 compared to chances of dropping out or attaining a degree. The hazard probability profiles, however, suggest a notable difference in the last two years in the dropout and degree attainment proportions. While the risk for dropping out is higher for classroom-only students, it becomes lower for online students relative to the chances for degree attainment.

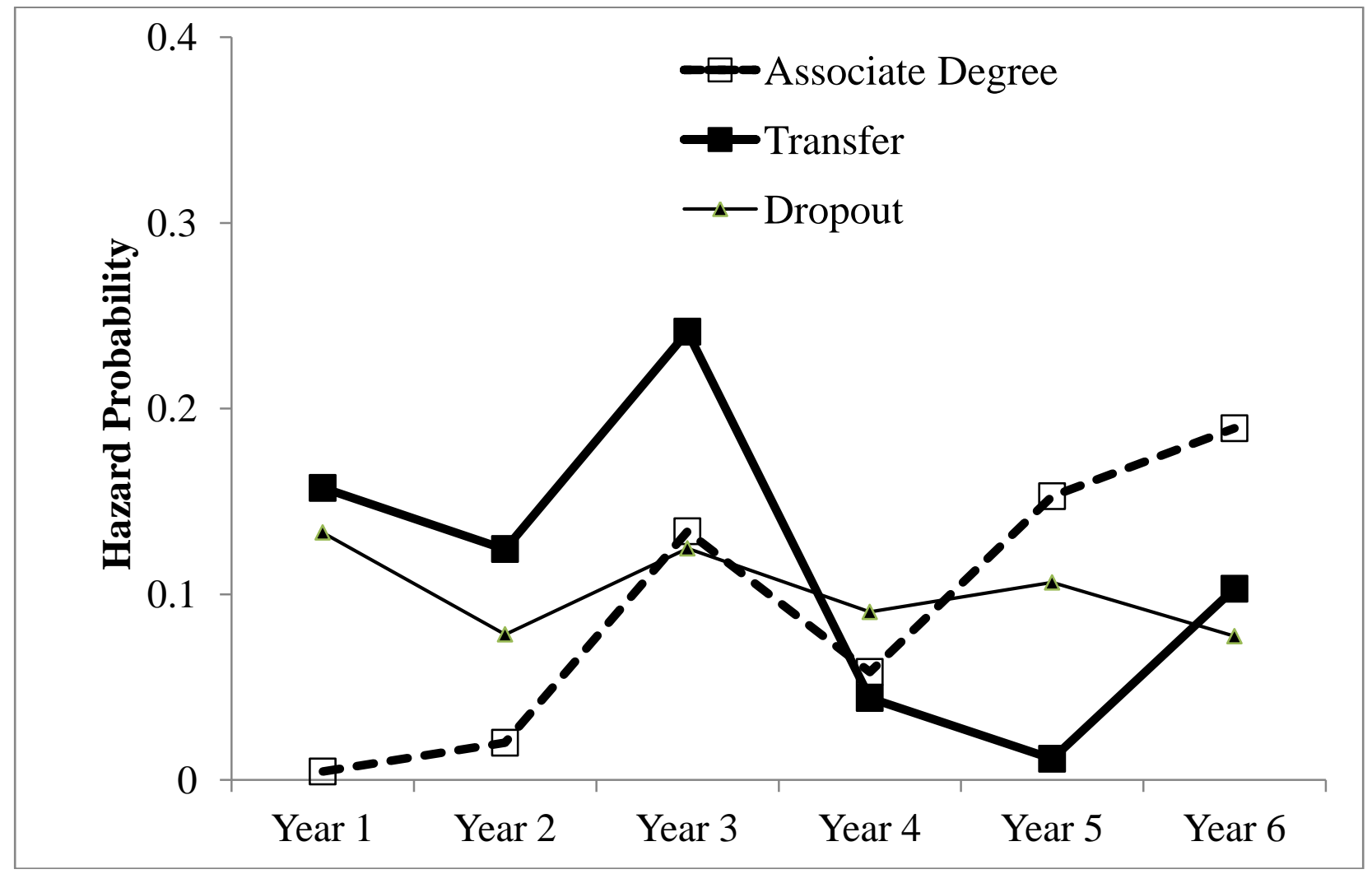

Figure 1A. Online Education Students 
A National Study of Differences between Online and Classroom-Only Community College Students in Time to First Associate Degree Attainment, Transfer, and Dropout

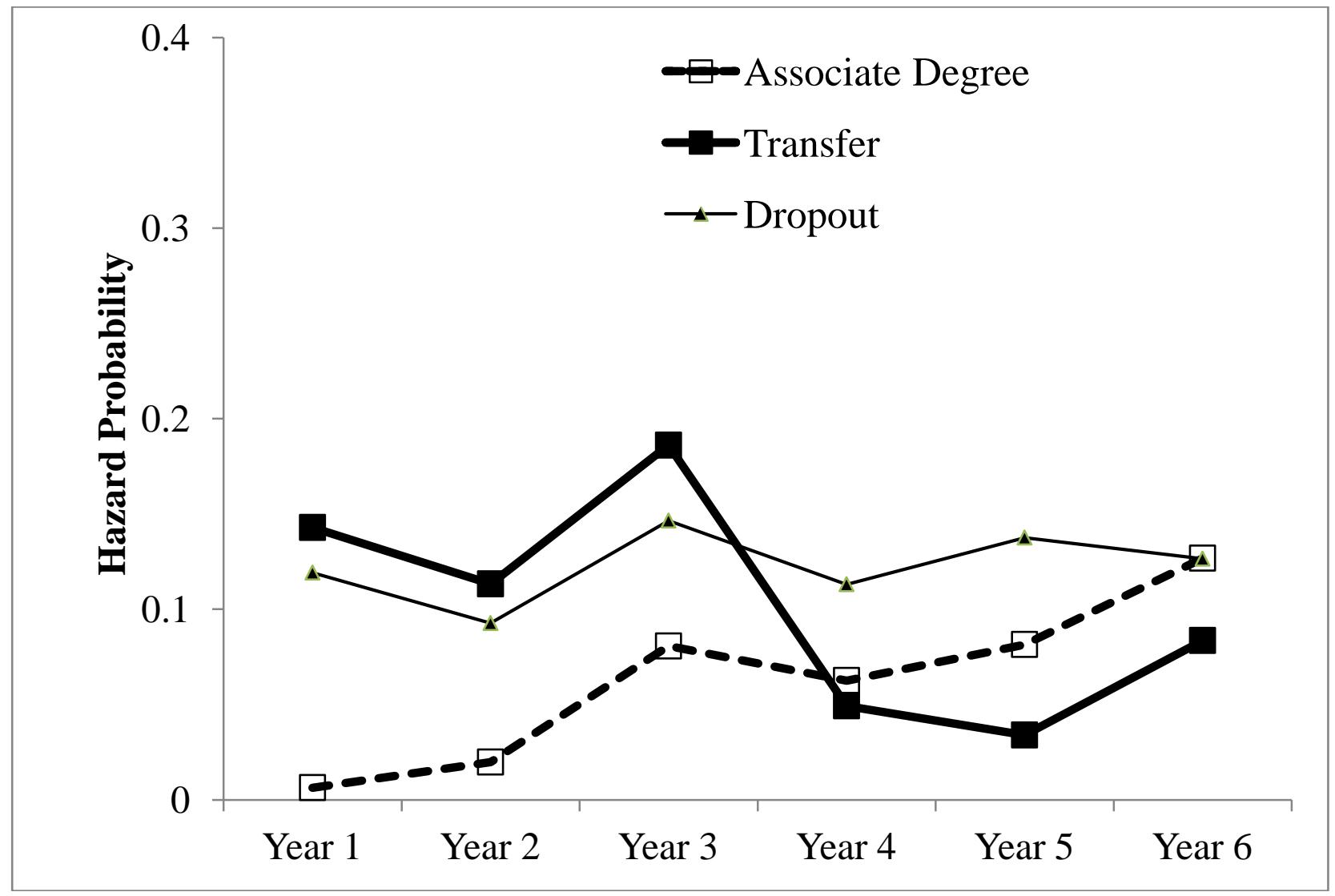

Figure 1B. Non Classroom-Only Education Students

Figures 2.A. and 2.B present the cumulative probability profiles for the two subpopulations. These profiles allow a better representation of how the processes unfold over time (Scott \& Kennedy, 2005). For each time period the graphs show the proportion of the original population that has experienced each event by that time period. The risk for all three outcomes increases steadily from year 1 to year 3 and then levels off for both subpopulations. There is a little change in the proportion of students (out of the original subpopulation of students) who graduate, transfer or dropout. By year 3, 9.203\%, $37.71 \%$, and $25.68 \%$ of the initial pool of online students have attained an associate degree, transferred, or dropped out respectively. The comparative percentages for the classroom-only students are $6.66 \%$, $33.12 \%$, and $27 \%$. Compared to the subpopulation of classroom-only students, a greater proportion of the original population of online students have attained an associate degree at the end of the observation period [online: 17.23\%, classroom-only: 13.27\%) and transferred [online: 40.83\%, classroom-only: 37.24\%]. Also, the cumulative dropout proportions at year 6 are higher for the classroom-only students [online: 36.73\%, classroom-only: 31.73\%]. Log rank tests assessing differences in the cumulative probability curves suggest a more accelerated rate of degree attainment, $\chi^{2}(d f=1)=6.14, p=.013$ but not for transfer $\chi^{2}(d f=1)=2.68, p=.102$ and dropout $\left[\chi^{2}(d f=1)=.199, p=.656\right]$. 
A National Study of Differences between Online and Classroom-Only Community College Students in Time to First Associate Degree Attainment, Transfer, and Dropout

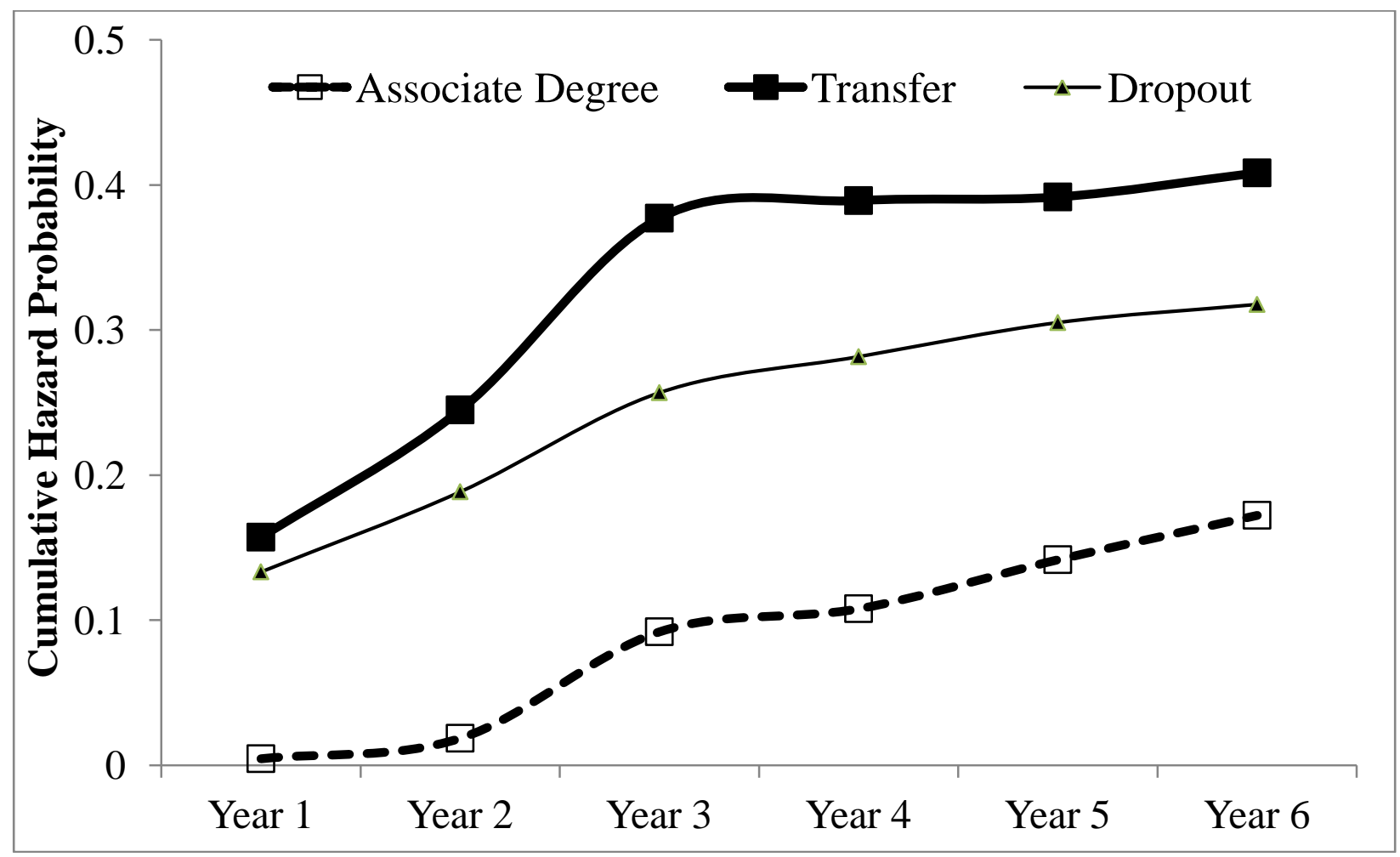

Figure 2A. Online Education Students

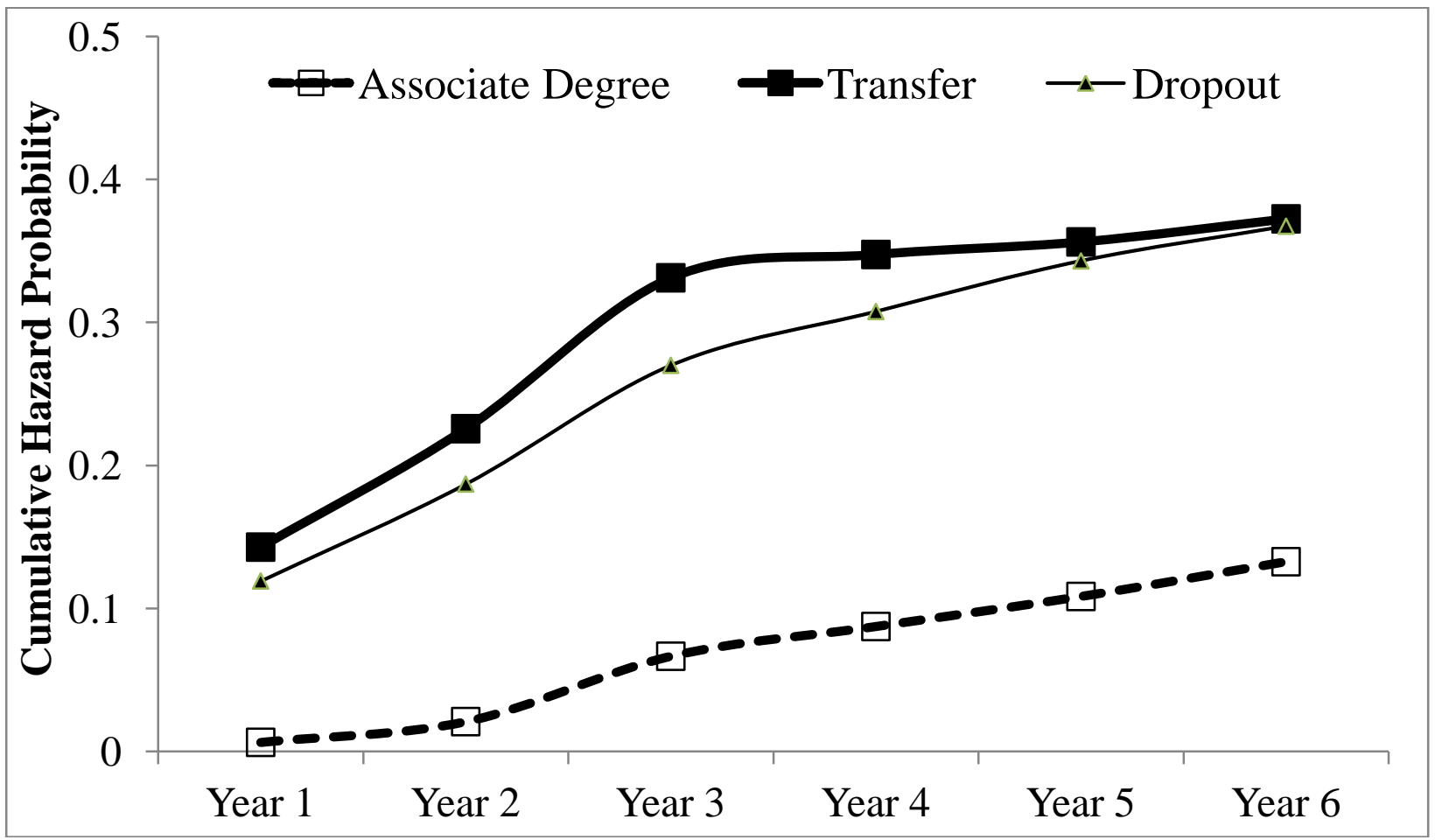

Figure 2B. Classroom-Only Students 
A National Study of Differences between Online and Classroom-Only Community College Students in Time to First Associate Degree Attainment, Transfer, and Dropout

In a follow-up analysis we examined if online and classroom-only students differ on any of the demographic characteristics (listed in Table 1) to determine if further subgroup analysis is warranted. Results indicated that there were no subpopulation differences in terms of age of first enrollment [Wald $F$ $(1,200)=2.183, p=.141$, socio-economic status as measured by adjusted family income in 2003/04 [Wald $F(1,200)=0.00, p=.992$ ], race [Wald $F(4,197)=1.886, p=.114$ ], and number of risk factors [Wald $F(1,200)=.747, p=.388$ ]. Female students, however, were more likely to be in online courses, Wald $F(1,200)=6.625, p=.011$. The effect of gender on time-to-events was therefore further considered in conjunction with type (online courses vs. classroom-only). To this end, each subpopulation was stratified based on gender, and the cumulative hazard probabilities were estimated for each gender online combination.

Female students tend to attain an associate degree earlier, regardless of type of coursework, $\chi^{2}$ $(d f=1)=16.2, p<.001$. Although the process is less accelerated for male students in general, classroomonly students appear to be at a particular disadvantage as their time to degree is longer than this for any other subpopulation [vs. male online, $\chi^{2}(d f=1)=4.85, p=.028$; vs. female classroom-only, $\chi^{2}(d f=1)=$ 13.8, $p<.001$; vs. female online, $\chi^{2}(d f=1)=16.5, p<.001$ ]. Figure 3 illustrates these differences.

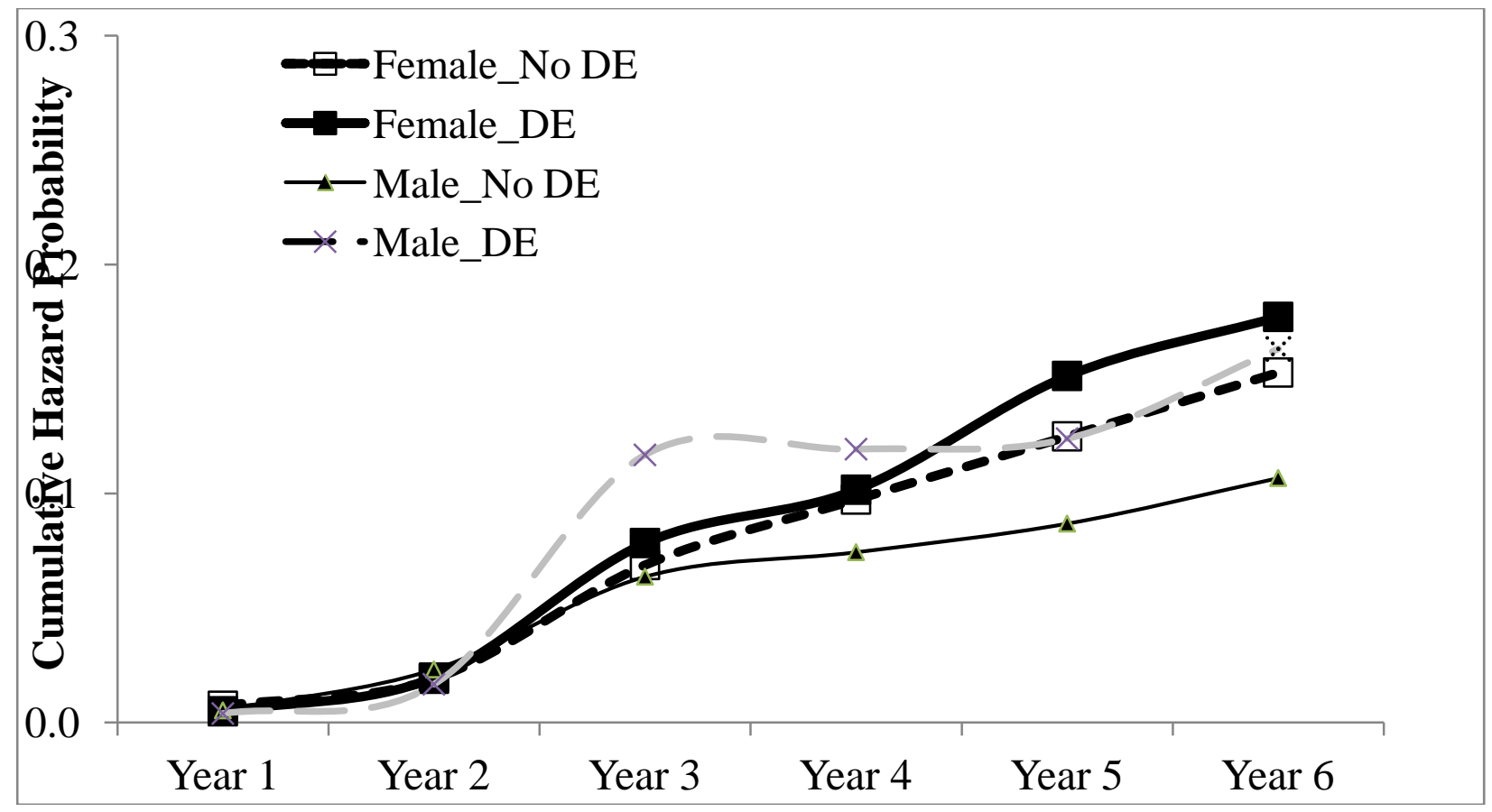

Figure 3. Time-to-degree by Type (Online Education vs. No) and Gender

\section{Discussion}

Contrary to negative results reported previously (Xu \& Smith Jaggars, 2011; Smith-Jaggars \& $\mathrm{Xu}, 2010)$, this study provides evidence that the time-to-degree process is more accelerated for students who participated in online study. Gender also explains variability in time-to-degree; female students are more likely to attain an associate degree in their first community college institution. As seen in previous studies (NCES, 2010), the transfer rates for students taking online courses are higher than attainment and dropout rates; this trend, however, does not appear to be alarming for a significant proportion of the transfer students (classroom-only: 22.86\%; online: 27.14\%) continue their education and receive a subsequent bachelor's degree. The higher rates of transfer and subsequent degree completion are also congruent with recent findings in the California Community College System (Johnson \& Cuellar Mejilla, 2014). 
A National Study of Differences between Online and Classroom-Only Community College Students in Time to First Associate Degree Attainment, Transfer, and Dropout

Of importance also is the finding that participation in online coursework does not contribute significantly to more pronounced dropout trends beyond what is considered typical for community college students. These national level findings do not confirm previous investigations indicating higher levels of dropout among students taking online coursework but does align with more recent research by James, Swan and Daston (2016) indicating no significant differences in retention. Contrary to the conclusion that students who took higher proportions of online courses were slightly less likely to attain a degree or transfer to a four-year college than those who took fewer online courses (Jaggars, 2012) we found that online course-taking is associated with higher and faster degree completion and no significant differences in dropout or transfer.

The study was limited to three competing events (first associate degree, dropout and transfer) among an array of other possible events such as completion of a degree other than associate, and/or return after several years of withdrawal from the institution of first entry. Design features (the study's length of six years and the insufficient sample size of online students) prevents a more detailed and informative analysis of alternative pathways of college success. In addition, the study did not consider some important closely related factors such as temporal withdrawal (stopout) and length of enrollment spells. The goal of this study was to model the real time-to-event processes at the institution of first enrollment; hence the inclusion of all students, regardless of actual stopout status or length of enrollment is justifiable. In addition, it should be noted that this study is primarily descriptive; future research should attempt to pinpoint the impact of factors such as employment histories, year-to-year fluctuation in employment, and changes in financial aid status and their time-varying effects on each of the three outcome variables. All of these factors may bear important consequences for degree attainment, transfer, or dropout and may contribute to a better understanding of the underlying risk mechanisms for each of these related outcomes.

These results extend research indicating small yet beneficial effects of online (Zhao et al., 2005; Means et al., 2009). Reviews of research in this area have found few significant differences in outcomes with more recent work suggesting modest benefits for online learners when specific conditions are met. These include course designs that ensure higher levels of interaction, embedded support for metacognitive strategies, and asynchronous formats (Zhao et al. 2005; Means et al., 2009). Additional work is needed to understand whether students who took online courses met these conditions or whether those who did enjoyed additional benefits not evident in this data.

Results indicating differences by gender are particularly interesting. This national data suggests that women are taking more online courses than men and graduating faster. The results also indicate that men who did not take any online courses fare worst in the attainment of a college credential, i.e. men taking some online courses graduate faster than men who do not. Women graduate faster in either condition but graduate most quickly when they took at least some online courses. These results deserve careful consideration and continued study.

While we do not believe online learning in any form is a panacea for the myriad challenges confronting higher education, these results provide a small degree of promise indicating that many years of effort and investment in online educational infrastructure were not wasted. These findings suggest that continued investment in and experimentation with online education may confer ongoing incremental benefits in assisting US college students to attain the many advantages associated with earning a college credential. We believe there is justification to briefly celebrate these modest achievements. Our conclusion that community college learners who take advantage of online course offerings appear to have a significantly higher six-year degree completion rate, and no significant differences in dropout compared with students who do not participate in online education is a small but meaningful accomplishment in an era recently characterized by hype, zeal, and overpromise in online education. 
A National Study of Differences between Online and Classroom-Only Community College Students in Time to First Associate Degree Attainment, Transfer, and Dropout

\section{References}

Allen, E. \& Seaman, J. (2004). Enter the mainstream: The quality and extent of online education in the United States 2003 and 2004. Babson Park, Mass.: Babson Survey Research Group and Quahog Research Group.

Allan, I.E. \& Seaman, J. (2013). Changing course: Ten years of tracking online education in the United States. Babson Park, Mass.: Babson Survey Research Group and Quahog Research Group.

Brooks, D. (2012, May 4). The campus tsunami. The New York Times, A29. Retrieved from http://www.nytimes.com/2012/05/04/opinion/brooks-the-campus-tsunami.html

Jaggars, S.S. (2012). “Online learning in community colleges. In Handbook of Distance Education (3rd ed.), edited by Michael G. Moore, 594-608. New York: Routledge.

Jaggars, S.S., Edgecombe, N., \& Stacey, G.W. (2013). What we know about online course outcomes. Community College Research Center, Teachers College, Columbia University, April 2013, 1-8.

Jaggars, S.S., \& Xu, D. (2013). Predicting online student outcomes from a measure of course quality (Working Paper 57). New York, NY: Community College Research Center, Teachers College, Columbia University.

James, S., Swan, K., \& Daston, C. (2016). Retention, Progression and the Taking of Online Courses. Online Learning, 20(2). Retrieved from http://olj.onlinelearningconsortium.org/index.php/olj/article/view/780/204

Johnson, H. \& Cuellar Mejilla, M. (2014). Online Learning and Student Outcomes in Community Colleges Public Policy Institute of California.

Muthén, B., \& Masyn, K. (2004). Discrete-time survival mixture analysis. Journal of Educational and Behavioral Statistics, 30(1), 27-58.

National Center for Education Statistics (2010). Persistence and Attainment of 2003-04 Beginning Postsecondary Students: After 6 Years: First Look (NCES 2011-151). U.S. Department of Education.

National Center for Education Statistics (2011). Projections of Education Statistics to 2020. U.S. Department of Education.

Organization for Economic Cooperation and Development (2013). Education at a Glance 2013: OECD Indicators. US Country Notes. Downloaded from:

http://www.oecd.org/edu/United\%20States\%20_EAG2013\%20Country\%20Note.pdf

Pappano, L. (2012, November 2). The year of the MOOC. The New York Times, ED26. Retrieved from http://www.nytimes.com/2012/11/04/education/edlife/massive-open-online-courses-are-multiplyingat-a-rapid-pace.html

Parsad, B., and Lewis, L. (2008). Distance education at degree-granting postsecondary institutions: 200607 (NCES 2009-044). National Center for Education Statistics, Institute of Education Sciences, U.S. Department of Education. Washington, DC. 
A National Study of Differences between Online and Classroom-Only Community College Students in Time to First Associate Degree Attainment, Transfer, and Dropout

Radford, A. (2011). Learning at a distance undergraduate enrollment in distance education Courses and Degree Programs (NCES 2012-154). National Center for Education Statistics, Institute of Education Sciences, U.S. Department of Education. Washington, DC.

Russell, A. (2010). A guide to major U.S. college completion initiatives. American Association of State Universities and Colleges.

Scott, M. A., \& Kennedy, B. B. (2005). Pitfalls in pathways: Some perspectives on competing risks event history analysis in education research. Journal of Educational and Behavioral Statistics,30, 413- 442. DOI: 10.3102/10769986030004413

Shea P. \& Bidjerano, T. (2014). Does online learning impede degree completion? A national study of community college students. Computers and Education, 75 (2), 103-111.

Singer, J. D., \& Willett, J. B. (2003). Applied longitudinal data analysis: Modeling change and event occurrence. New York: Oxford University Press.

Sparks, S. (2011, September 13). U.S. postsecondary edge shrinking among G-20 countries. Education Week.

Vaughan, G. B. (2006). The community college story. Washington, DC: Community College Press.

Xu, D., \& Jaggars, S. S. (2013). Adaptability to online learning: Differences across types of students and academic subject areas. (CCRC Working Paper No. 54). Community College Research Center. Teachers College, Columbia University. 